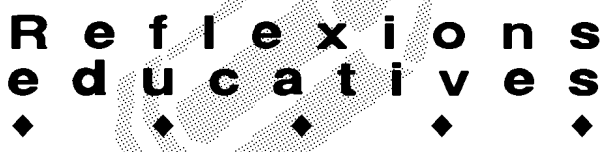

\section{LA PSICOMOTRICITAT EN EL MARC DE L'EDUCACIÓ INFANTIL}

\author{
Isabel Viscarro Tomàs. Àrea de Didàctica de I'Expressió Corporal. URV
}

\begin{abstract}
La importància del cos, el moviment i l'acció per al desenvolupament integral de l'infant, especialment a les primeres edats (Educació Infantil) és coneguda per tothom. Tot $\mathrm{i}$ això, considerem que la presència del treball corporal a l'escola és escasa, ja que en aquesta etapa no podem reduir l'activitat lúdica, corporal i expressiva a una sessió d'una hora a la setmana. Aquesta activitat a través del joc, l'acció i l'experimentació afavoreix el procés de construcció del coneixement, i aquest tindrà un caràcter constructiu a mesura que el nen/a en descobreixi propietats i relacions de les persones i elements del món que l'envolta.

En aquest article pretenem justificar la importància de l'Educació Psicomotriu com una estratègia d'intervenció educativa que està en clara sintonia amb els postulats del Disseny Curricular Base per a Educació Infantil. Voldríem destacar l'absència del terme psicomotricitatal currículum, tot i que si en fem una anàlisi es pot comprovar que els objectius, continguts, i situacions d'aprenentatge inclouen els aspectes relatius a aquest àmbit d'experiència de la realitat global de l'infant.
\end{abstract}

Entenem que la psicomotricitat no ha de ser una matèria aïllada del programa educatiu, sinó una metodologia pensada per assolir uns objectius educatius: afavorir el desenvolupament integral de l'infant que sorgeix de la utilització del cos i el seu moviment. Per tant, si pretenem que hi hagi una coherència educativa, l'acció pedagògica no es pot limitar a treballar els blocs de continguts de l'àrea I: "Descoberta d'un mateix" ja que tots ells es poden abordar des d'un plantejament de treball psicomotor i són propis de la psicomotricitat, sinó que, a partir de les vivències, situacions de joc i relacions que sorgeixen a les sessions, s'haurien també de recollir i aprofitar per plantejar activitats referides als blocs de continguts de les àrees II: Descoberta de l'entorn natural i social" i III: "Intercomunicació i llenguatges".

El Currículum d'Educació Infantil i la Pràctica Psicomotriu Educativa tenen molts punts en comú. N'exemplificarem alguns extrets de les capacitats a assolir en finalitzar l'etapa.

"Assolir el grau de seguretat afectiva i emocional que correspon al seu moment maduratiu i anar-se formant una imatge positiva d'ells mateixos i dels altres".
La pràctica psicomotriu preten afavorir el desenvolupament de la segurització profunda de l'infant a partir de la seva expressivitat psicomotriu. El nen /a s'expressa corporalment i emocionalment a partir de la seva acció i reb el mirall dels altres.

El currículum també diu: "Progressar en el coneixement $\mathrm{i}$ domini del seu cos $\mathrm{i}$ de les possibilitats motrius, sensitives i expressives".

La sessió de psicomotricitat és un camp d'experimentació privilegiat. És el lloc on els infants poden viure el plaer sensoriomotor en totes les seves possibilitats: es desplacen de diferents maneres, salten, giren, s'equilibren i es desequilibren, pujen i baixen, s'amaguen, juguen amb pilotes, cèrcols, robes, coixins..., reposen, esperen. Descobreixen les propietats dels objectes a partir de la manipulació, construeixen amb mòduls d'escuma, amb fustes, amb estructures de plàstic, etc.

En les capacitats a assolir també hi trobem: "Representar i evocar aspectes de la realitat viscuda, coneguda o imaginada i expressar-los mitjançant les possibilitats simbòliques...".

Aquests aspectes es treballen al final de la sessió de psicomotricitat en el que Aucouturier (1991) anomena "temps d'expressivitat plàstica i llenguatge", on s'ofereixen a l'infant diferents materials per dibuixar, modelar, o simplement poder parlar d'allò que acaben de viure. Potenciant d'aquesta manera la interiorització, la representació i la reflexió.

\section{Interrelació de les àrees i la seva vinculació amb la psicomotricitat}

$\mathrm{Al}$ referir-nos als "àmbits d'experiència" 0 "àrees curriculars", volem fer un plantejament des de la globalitat partint del que l'infant és (actitud), fa (procediment) i sap (concepte) en aquestes tres árees curriculars interrelacionades.

Tenint en compte aquest criteri i segons l'edat de l'infant, considerem que la distribució dels blocs de continguts que corresponen a cada àrea tindrà més 0 menys pes, de forma que existeix una gradació creixent o decreixent en funció de quina àrea sigui, com queda reflectit a la figura 1. 


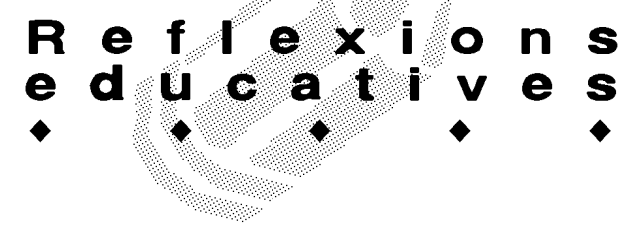

Les dues grans unitats de significació per a la infància son: un mateix i l'entorn; per això pensem que les àrees | "Descoberta d'un mateix" i || "Descoberta de l'entorn natural i social" tenen un pes més important des de les primeres edats. Pel que fa a l'àrea III "Intercomunicació i llenguatges", hem de tenir en compte que els lleguatges tònic, gestual i postural es desenvolupen des del naixement, però si ens referim al nivell representatiu, implicant el desenvolupament i l'ús de la funció simbòlica, apareix posteriorment (entre els 18 i els 24 mesos). Aquesta àrea té una funció mediadora en les relacions entre l'individu i el medi, els diferents llenguatges són els instruments que possibiliten les interaccions, el coneixement i la representació.

\section{Primer cicle d'Educació Infantil (0-3)}

Al llarg d'aquest cicle a l' àrea "Descoberta d'un mateix", és a la que correspon més pes, donada la importància que tenen en aquestes edats els blocs de continguts que inclou. La vivència del cos i del moviment és el primer pas per poder accedir al coneixement i a la comunicació amb l'entorn. A mesura que el nen/a va evolucionant, aquesta distribució anirà variant, anirà

\begin{tabular}{|c|c|c|c|}
\hline Edat & $\begin{array}{l}\text { ÀREA I } \\
\text { DESCOBERTA } \\
\text { D'UN MATEIX }\end{array}$ & $\begin{array}{l}\text { ÀREA II } \\
\text { DESCOBERTA DE } \\
\text { L'ENTORN NATU- } \\
\text { RAL I SOCIAL }\end{array}$ & $\begin{array}{l}\text { ÀREA III } \\
\text { INTERCOMUNICACIÓ } \\
\text { I LLENGUATGES }\end{array}$ \\
\hline $0-1$ & $\Leftrightarrow$ & a & \\
\hline $1-2$ & & & \\
\hline $2-3$ & & & \\
\hline $3-4$ & & & \\
\hline $4-5$ & & & \\
\hline $5-6$ & & & \\
\hline $6-7$ & $\Leftrightarrow=1$ & & \\
\hline $7-8$ & $\Rightarrow$ & 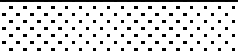 & \\
\hline
\end{tabular}

Fig. 1. Distribució dels blocs de continguts de cada àrea curricular

decreixent l'àrea I i anirà augmentant progressivament el pes de l'àrea III, donat que les seves capacitats de comunicació augmenten i s'enriqueixen, l'infant cada vegada utilitza més i millor els llenguatges.

En aquest àmbit d'experiència es facilita que el nen/ a pugui experimentar la vivència del cos i del moviment amb plaer, a partir de la seva activitat motriu espontània, bàsicament sensòriomotriu.

Al llarg del cicle, l'infant va adquirint de manera progressiva el coneixement, domini i acceptació del propi cos. Estableix la diferència entre ell mateix i les persones que l'envolten, també va guanyant autonomia en les rutines i activitats quotidianes.

L'adquisició progressiva de la coordinació li proporciona precisió i soltesa en les habilitats perceptives i motores, aprèn a desplaçar-se de maneres diferents, pot accedir de manera més autònoma als objectes i progressar en el desenvolupament del coneixement del món, a la vegada que li proporciona més independència respecte a l'adult. Tot això li permet identificar la unitat $i$ globalitat del seu cos i la diferenciació entre aquest i l'espai dels objectes i les persones.

Les conquestes en referència al llenguatge li permeten progresar en la comunicació tant amb els companys com amb els adults,a través de l'expressió de sentiments, emocions, idees, experiències, etc.

En aquesta àrea l'Educació Psicomotriu és fonamental; es més, jo diria que és l'única via per poder treballar els continguts, sobretot els procedimentals, sense deixar de banda els actitudinals i conceptuals.

La intervenció psicomotriu en aquestes edats s'ha de fonamentar en la comunicació i el plaer sensoriomotor, tenint en compte dos periodes diferenciats: el primer, des del naixement fins que comencen a caminar. El segon, des de que caminen fins que comencen a còrrer, al voltant dels dos anys. En aquest segon període hi ha un canvi important en l'infant, l'alliberació del cos i del moviment en còrrer, també l'hi permet l'alliberació de les emocions. Les rialles que acompanyen l'acció i la seva expressivitat facial manifesten aquesta emoció (AUCOUTURIER, 1991).

Així doncs, a la sala de psicomotricitat els nens i nenes exploren les seves possibilitats que al principi són molt tòniques i properes a terra, utilitzant sovint objectes tous per fer: balancejos, girs, salts, pressions, equilibris i desequilibris...; també experimenten diferents maneres de desplaçar-se (caminen, corren, salten, s'arrosseguen, repten, rodolen, fan construccions senzilles amb les peces d'escuma.

Com s'ha comentat anteriorment, entre els 18 i els 24 mesos, existeix una relació important entre el moviment i la representació mental i s'haurien d'afavorir els jocs pressimbòlics com l'aparèixer/desaparèixer, omplir/buidad, entrar/sortir, pujar/baixar, obrir/tancar, etc.

Totes aquestes activitats que realitza el nen/a, conjuntament amb l'actitud de l'adult (no directivitat, permisivitat, donar seguretat, acceptació, contenció, respecte a les produccions dels infants i de reconeixement), facilitaran el control progressiu del propi cos, la formació d'una autoimatge positiva i la capacitat d'autoestima i autonomia.

L' àrea de "Descoberta de l'entorn natural i social" pràcticament sempre té el mateix pes; l'infant va desco- 


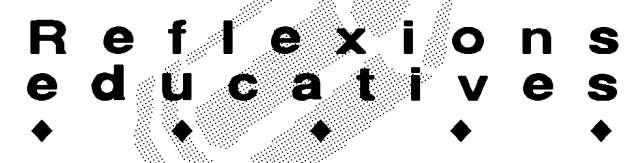

brint la seva identitat i autoimatge gràcies a la seva interacció amb el medi social i natural, que va descobrint, pràcticament, al mateix temps. Aquest cicle li suposa l'ampliació del nucli familiar i les persones que en formen part. Es pretén que el nen/a ampliï i conegui progressivament el seu medi, incloent-hi els elements de l'entorn, que s'adapti progressivament a la vida de grup i que tregui el màxim profit dels objectes, estímuls i situacions que es posen a la seva disposició.

Les experiències que li faciliten els diferents objectes, juntament amb el desenvolupament progressiu de les capacitats motrius, li permeten descobrir, observar i explorar nous universos. Les sessions de psicomotricitat poden preparar i desenvolupar diferents continguts d'aquesta àrea, especialment els procedimentals.

En referència a l'àrea III: "Intercomunicació i llenguatges", cal recordar que l'infant, molt abans d'expressar-se amb el llenguatge verbal, ho fa amb el corporal.

L'edat primerenca dels nens i nenes d'aquest cicle fa que els instruments de comunicació verbal, al principi, siguin molt rudimentaris, però en canvi són capaços de

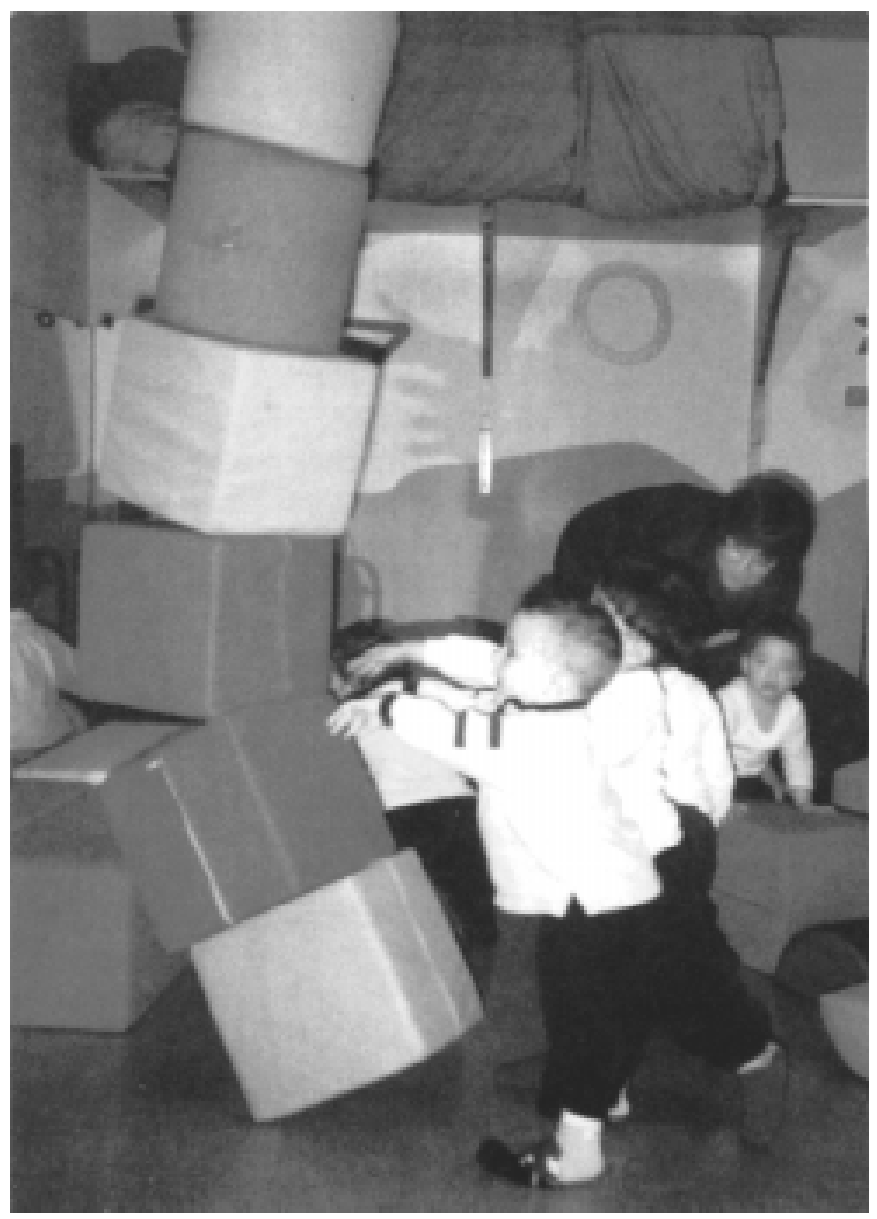

comunicar-se per mitjà del gest, de l'expressió i entre els 2 i 3 anys la comunicació per la paraula va guanyant importància...

L'activitat de l'infant sobre els objectes anirà variant a mesura que el nen accedeixi al llenguatge com a instrument de comunicació; anirà substituint el contacte directe dels objectes per la seva representació mental.

El llenguatge verbal s'anirà convertint, de manera progressiva, en l'instrument privilegiat, tot i que no hauria d'anar en detriment de la comunicació corporal (mirada, gestos...). Tal com diu Le Boulch (1997): "Psicomotricitat i llenguatge estan relacionats en el desenvolupament de les funcions gnòsiques. La comprensió de les relacions espacials i dels conceptes d'orientació és, en gran mesura, el resultat de l'activitat motriu d'exploració. No obstant això, la verbalització és necessària per fixar l'experiència, és a dir, per la seva memorització, de la mateixa manera que per a la percepció temporal i la representació mental del fets successius" (pàg. 256).

En aquest cicle s'haurien d'aprofitar totes les situacions vinculades al joc i a les rutines diàries perquè el llenguatge oral es converteixi en element útil de relació i comunicació interpersonal. Durant les sessions de psicomotricitat els diferents llenguatges hi són presents. El llenguatge corporal, tònic, gestual i postural, no cal dir que són els més utilitzats, ja que és la base dels altres llenguatges i constitueix l'essència del treball psicomotriu.

\section{Segon cicle d'Educació Infantil (3-6)}

Pel que fa a aquest cicle, el pes atorgat a cadascuna de les àrees varia lleugerament en relació al cicle anterior. Com podem observar al gràfic, els blocs de continguts de l'àrea III van guanyant importància, mentre que els de l'àrea I van decreixent de manera progressiva i es manté l'àrea II aproximadament igual que en el cicle anterior.

Aquest cicle és una continuïtat de l'anterior, on es van consolidant i ampliant les primeres adquisicions. En aquest període es desenvolupa la capacitat d'interactuar intel-ligentment amb el medi mitjançant esquemes representatius, i l'acció motriu comença a completar-se i ser substituïda per l'acció mental. No obstant això, encara persisteix en aquestes edats la indiferenciació entre el "jo" i el "món", amb el que Piaget denomina "egocentrisme" que es manifesta de diferents formes: animisme, artificialisme, realisme, finalisme, llenguatge egocèntric, etc.

Els nens/es al llarg del cicle perfeccionen la capacitat d'anàlisi perceptiva, així com les habilitats sensoriomotrius. Així doncs, les sessions de psicomotricitat, plantejades a partir de l'activitat motriu espontània del 


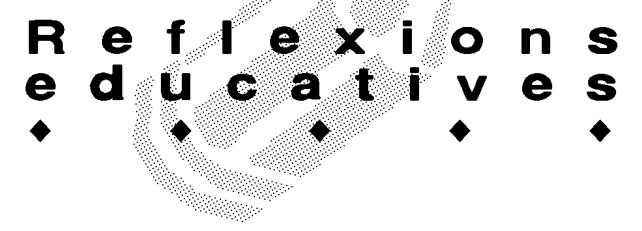

infant, li permeten manifestar-se tal com és, en llibertat, afavoreixen la seva creativitat, el desenvolupament i l'organització, amb els materials i objectes que tenen a disposició, i els jocs i activitats que es realitzen a la sala.

Observar l'evolució de l'equilibri i la coordinació tant general com específica en diverses activitats on s'enfilen molt i salten, fan suspensions (conquesta de l'alçada)...; manipulen els objectes: Ilancen i agafen pilotes, les fan botar, fan punteria, fan nusos amb les cordes; van prosperant en la capacitat de prendre decisions, acords i de buscar solucions als problemes que van sorguint en els jocs, cada vegada amb menys ajut de l'adult. Això no vol dir que aquest no sigui tan necessari, ho segueix sent tant com hem comentat abans en el cicle (0-3), però la seva intervenció s'haurà d'anar ajustant a les necessitats i demandes dels infants i del grup, que en cada edat i situació són diferents. (àrea I).

La seva participació social va augmentant tant en quantitat com en qualitat. Passa del joc individual 0 paral-lel al joc cooperatiu i s'incrementa la capacitat de representació (àrees II i III). Gaudeix de la descoberta del món que l'envolta, construeix la noció d'objecte i estableix relacions, correspondències, i comparacions entre ells (àrea II).

Realitza contínuament processos d'assimilació i acomodació. La seva fonologia es va ajustant, el lèxic va augmentant, millora la creativitat sintàctica i l'enunciat de les frases, passant d'estructures senzilles a més complexes (àrea III).

Els jocs presimbòlics i simbòlics afavoreixen la relació entre els mateixos companys/es i entre ells i l'adult. Els jocs que realitzen solen ser molt rics en experìències, facilitant a l'infant molta informació. Els nens i nenes es disfressen amb trossos de roba simbolitzant personatges, es relacionen, respecten les normes, comparteixen, i expressen els seus sentiments, posant en joc la seva dimensió afectiva. Es tracta d'aprofitar aquestes situacions que es posen de manifest a la sala de psicomotricitat i fer-les servir de punt de partida a l'hora de treballar els continguts d'aquesta àrea, ja que la construcció del pensament es realitza a partir de les seves vivències, de les idees que manifesten quan juguen a les famílies, als metges, als mitjans de transport..., de les actituds i normes socials que apareixen en el joc, de l'exploració i manipulació de materials i objectes diversos, etc., i canalitzar-los cap a aprentatges conceptuals.

Pel que fa al llenguatge oral, es té en compte en tota la sessió, però de manera especial en dos moments: al principi, on els nens i nenes parlen del que poden fer, recorden jocs de sessions anteriors que volen continuar i fins i tot fan propostes de joc col-lectives; l'altre, al final de la sessió, quan un cop acabada l'activitat s'asseuen i posen paraules al que s'ha fet, de manera individual. D'aquesta manera afavorim el distanciament emocional d'allò que s'ha viscut i que és imprescindible per assolir progressivament el descentrament, és a dir, la capacitat de situar-se "fora" d'un mateix, de l'objecte o de la situació.

Aquesta representació del que acaben de viure, també la poden expressar per mitjà d'altres llenguatges: dibuix, pintura, modelat amb fang o plastilina, i també l'escriptura, ja sigui per part d'ells (segons l'edat) o per part de l'educador que pot anar escrivint el que ells diuen a la pissarra.

Es pretén treure el màxim d'aquest final de la sessió, ja que si som capaços d'estirar pot donar molt de si, i ens permet de treballar, a partir de la vivència, la majoria de continguts d'aquesta àrea. És el que proposen Lapierre i Aucouturier en el plantejament metodològic de la seva obra Educación vivenciada, on a partir del descobriment d'una determinada noció i la seva vivència, pretén que els nens i nenes la puguin expressar de diferents maneres (expressió amb el cos, el gest, el so, amb el dibuix, amb la paraula...).

Aquest itinerari evolutiu el porta a construir una imatge mental representativa del propi cos, de les seves postures i moviments; dels intercanvis que es produeixen entre ell/a i el medi, de les característiques dels objectes i persones que el componen. Aconsegueix fer-los presents quan no hi estan.

Com ja hem comentat anteriorment, al primer cicle, les sessions de psicomotricitat ens permeten continuar treballant de la mateixa manera els continguts de les àrees II i III, adaptats als requeriments del moment evolutiu dels nens i de les nenes.

Pensem que al llarg de l'article hem posat de manifest les estretes relacions entre les tres àrees curriculars que configuren la realitat del nen/a i la realitat és global.

\section{Bibliografia consultada}

ARNAIZ, V. La reforma i la pràctica psicomotriu. «Pissarra» 62 (1992) 29-31.

AUCOUTURIER, B. Conferencia inagural de les IX Jornades de Pràctica Psicomotriu. Barcelona, 1991.

BASSEDAS, E., HUGUET, T. i SOLÉ, I. Aprendre i ensenyar a l'educació infantil. Editorial Graó. Barcelona. 1996.

GENERALITAT DE CATALUNYA. Curriculum Educació Infantil. Departament d'Ensenyament. Barcelona. 1991.

LAPIERRE, A. i AUCOUTURIER, B. Educación vivenciada (3 volums). Editorial Científico-médica. Barcelona. 1977.

LE BOULCH, J. El movimiento en el desarrollo de la persona. Editorial Paidotribo. Barcelona. 1997.

LLORCA, M. i VEGA, A. Psicomotricidad y globalización del currículum de educación infantil. Editorial Aljibe. Málaga. 1998. 